\title{
Performance Comparison of Cost Efficient Natural Dye Sensitized Solar Cell
}

\author{
Afshana Afroj Bristi ${ }^{1,}$, , S. M. Jahadun-Nobi ${ }^{2}$, Md Nurul Abser ${ }^{1}$, Md Mehadi Hassan ${ }^{3,4}$ \\ ${ }^{1}$ Department of Chemistry, Jahangirnagar University, Savar, Dhaka, Bangladesh \\ ${ }^{2}$ Department of EEE, Noakhali Science and Technology University, Sonapur, Noakhali, Bangladesh \\ ${ }^{3}$ Department of Chemical and Petroleum Engineering, University of Calgary, AB, Canada \\ ${ }^{4}$ Department of Arts and Sciences, Bangladesh Army University of Science and Technology, Saidpur, Nilphamari, Bangladesh
}

\section{Email address:}

bristiju14@gmail.com (A. A. Bristi),smjnobi@yahoo.com (S. M. Jahadun-Nobi), abserju@ymail.com (Md N. Abser), mdmehadi.hassan@ucalgary.ca (Md M. Hassan)

${ }^{*}$ Corresponding author

\section{To cite this article:}

Afshana Afroj Bristi, S. M. Jahadun-Nobi, Md Nurul Abser, Md Mehadi Hassan. Performance Comparison of Cost Efficient Natural Dye Sensitized Solar Cell. American Journal of Electrical Power and Energy Systems. Vol. 9, No. 4, 2020, pp. 60-66.

doi: 10.11648/j.epes.20200904.11

Received: July 7, 2020; Accepted: July 22, 2020; Published: August 19, 2020

\begin{abstract}
Dye-sensitized solar cells (DSSCs) enticed the attention in photovoltaic design due to their unique features of ease of fabrication, low-cost materials, tunable color, and flexibility. In this work, we studied the performance of a low cost dye-sensitized solar cell structure with several natural dyes as a sensitizer. Titanium dioxide $\left(\mathrm{TiO}_{2}\right)$ was used as the semiconducting layer. The $\mathrm{TiO}_{2}$ film was fabricated on Florine doped Tin Oxide (FTO) glass plate and was annealed and sintered for an hour at $450^{\circ} \mathrm{C}$ temperature to create a mesoporous layer. To reduce the manufacturing cost, we used Carbon black instead of Platinum (Pt) as a counter electrode. Carbon black provides excellent stability and shows high catalytic ability along with its low cost as the counter electrode in the DSSCs. Eight different dyes have been extracted and purified by Silica gel column chromatography to use in the DSSCs. UV-Visible absorption spectroscopy and fluorescence spectroscopy has been done to measure the absorbance coefficient and fluorescence coefficient of each of the cells. The cells with an additional peak in the fluorescence spectra showed much better electrical performance compared with others. Among the fabricated DSSCs, the Curcuma longa based DSSC gives the highest open-circuit voltage of $0.5959 \mathrm{~V}$ and short circuit current density of 1.06 $\mathrm{mA} / \mathrm{cm}^{2}$. The study also indicates that the dyes with a peak at $380 \mathrm{~nm}$ to $400 \mathrm{~nm}$ wavelength at fluorescence spectrum has better photovoltaic performance rather with a moderate absorbance spectrum.
\end{abstract}

Keywords: Dye-Sensitized Solar Cell, Natural Dye, Counter Electrode, Column Chromatography, Absorbance Coefficient, Fluorescence

\section{Introduction}

Developing affordable and efficient photovoltaic technologies has always been a cherished goal of materials scientists and device community. Exploring non-silicon alternatives based on the novel scientific opportunities afforded by the emergence of third-generation cells has gained significant momentum in this respect during the past two decades. The third-generation cells are designed to combine the advantages of both the first and second-generation devices. Concentrating photovoltaic technology, dye-sensitized solar cells (DSSCs), organic solar cells are some well-known third-generation photovoltaics. Dye-sensitized solar cells, a third-generation cell, are still in their productizing cycle and are extremely promising for their low cost, affordable and straightforward manufacturing process [1].

The dye-sensitized solar cell is a photo-electrochemical system based on a semiconductor formed between a photo-sensitized anode, and an electrolyte. Though the thermo-stability of DSSC with amphiphilic Ruthenium (Ru) sensitizer in conjunction with quasi-solid-state gel electrolyte 
makes these devices viable for practical application, they show a very less efficiency $[2,3,4,5]$. As the performance of the DSSCs much depends on the photosensitizer and counter electrode, it has been gone under various development over the years in order to find the effective photosensitizer to provide highest efficacy $[6,7]$.

Several numbers of dyes, e.g. inorganic and organic, metal-free dyes or natural dyes have been used over the years. Among them, N3, N719, N749 (black dye), K19, CYC-B11, C101, K8, D102, SQ, Y123, Z907, Mangosteen, and many more have been commonly utilized as sensitizers in DSSCs [8]. Moreover, replacing the expensive, toxic, and sophisticated dyes with low cost and eco-friendly dye is a promising option to make the DSSCs economically viable. Organic dyes based on porphyrin has been reported to have an efficiency of the order of $5.6 \%$ [9]. Hence, by considering the availability, environment-friendly nature, reduced cost and purification process, natural dyes are feasible photosensitizers with their considerable efficiencies.

Besides the performance of the sensitizer layers, the counter electrode (CE) has also affected the performance of DSSCs, as it influences the kinetic over potential [10]. The CE consists of Florine doped Tin Oxide (FTO) glass coated with Pt is commonly used because of its high catalytic activity towards the nanometer layer. As the thin layer of $\mathrm{Pt}$ is almost transparent, platinized counter electrodes can also be employed the reverse cell structures. Despite the advantages of $\mathrm{Pt}$, Its high value has created a barrier to use it in affordable PV structure. Other materials like graphite, carbon black on FTO glass and organic-ion doped conducting polymer of poly (3, 4-ethylene dioxythiophene) (PEDOT) on both ITO and FTO-glass have been employed as the counter electrode in DSSCs [11]. In this study, FTO glass coated with activated carbon is used as CE because of its affordability, more reversible electron transfer characteristic, and its chemically stable nature in the electrolyte.

In this work, Curcuma longa, Beta vulgaris, Rosa acicularis, Punica granatum, Alternanthera dentate, Bougainvillea spectabilis, Tectona grandis, Delonix regia are used as a source of photosensitizer for DSSCs. Among them, Curcuma longa shows the highest power output compared to others. To ensure the photosensitizer quality absorbance and fluorescence are compared, and the maximum power output in a 1.0 sun condition is observed. The remainder of this article is structured as follows: the preparation of DSSCs with the proposed natural dyes is described along with characterization and measurement procedure in section 2 . The results obtained in the present study are presented in section 3. Finally, the article ended with the conclusion in section 4 .

\section{Experimental Procedure}

Dye-Sensitized Solar cells involved in this study are fabricated using the following steps.

\subsection{Preparation of Natural Dye Sensitizers}

To prepare the dye, we used extract (rhizome, petals, leaves, or fruits) from Curcuma longa, Beta vulgaris, Rosa acicularis, Punica granatum, Alternanthera dentate, Bougainvillea spectabilis, Tectona grandis, Delonix regia. The collected samples were washed thoroughly with water and are dried in the hot air in order to remove the water. $20 \mathrm{~g}$ to $50 \mathrm{~g}$ of each of the sample was weighed and chopped into small pieces and crushed in mortar. The residue of the sample was filtered out to collect the dye solution. Extracted crude dye was stored in a clean beaker in a dark room. The extract was purified by using Silica gel column chromatography. Natural dyes, collected from Column Chromatography using ethanol as mobile phase, were stored in beakers.

\subsection{Preparation of Photo Electrode}

For the preparation of the photoelectrode, we used fluorine-doped tin oxide $\left(\mathrm{FTO}, \mathrm{SnO}_{2}: \mathrm{F}\right)$ as transparent conducting glass plate. Though the transmittance of FTO is less than indium doped tin oxide (ITO, $\operatorname{In}_{2} \mathrm{O}_{3}: \mathrm{Sn}$ ), the conductivity of FTO is almost double compared to ITO. Hence, for the superior conductivity, FTO has been chosen. As a thin layer of semiconducting oxide materials, $\mathrm{TiO}_{2}$ was used for its superior energy bandgap of $3.2 \mathrm{eV}$. Non-toxicity, availability in nature, and economic viability also influenced to choose $\mathrm{TiO}_{2}$. To prepare the $\mathrm{TiO}_{2}$ paste, we weighed $1 \mathrm{~g}$ of $\mathrm{TiO}_{2}$ powder and mixed and grinded well with distilled ethanol in a mortar using a clean pestle. For the preparation of suspension, we quantitatively maintain the ratio of $\mathrm{TiO}_{2}$ to liquid. The paste was deposited on the FTO glass and was coated by "doctor blade" method to spread the paste across the FTO unvaryingly. The $\mathrm{TiO}_{2}$ film on the conductive glass was annealed and sintered in a furnace (Muffle Furnace) for an hour at $450^{\circ} \mathrm{C}$ temperature for the creation of a mesoporous layer of $\mathrm{TiO}_{2}$ in FTO glass. After that, the furnace was turned off, and the slide was allowed to cool slowly to room temperature. Then it was put separately into one of the dye solutions, and allowed to be socked the dye for an hour. Absorption of the dye to the surface of $\mathrm{TiO}_{2}$ and complexion to Ti sites is rapid. As annealing of the $\mathrm{TiO}_{2}$ film creates a porous surface, the dye molecule covalently bonded with $\mathrm{TiO}_{2}$ in a rapid way. The unabsorbed dye was removed by rinsing with ethanol. It is essential that the dye has a good interaction with the $\mathrm{TiO}_{2}$ as a lack of interaction resulting in low loading in the surface of $\mathrm{TiO}_{2}$ films leads to a poor photovoltaic efficiency [12].

\subsection{Preparation of Counter Electrode}

A piece of conductive FTO glass was also used for preparing the counter electrode. With a tweezers the conductive side of the glass was placed at the top of a burner, to apply a light carbon film to the entire conductive side of the slide. This thin carbon layer serves as a catalyst for the $\mathrm{I}^{-}$/ $\mathrm{I}_{3}{ }^{-}$regeneration. 
a.

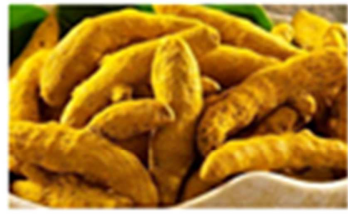

b.

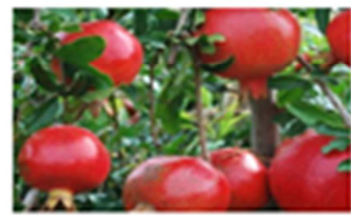

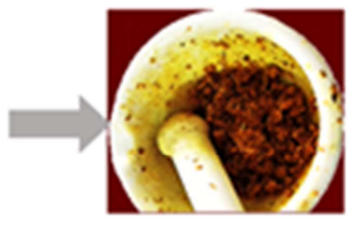

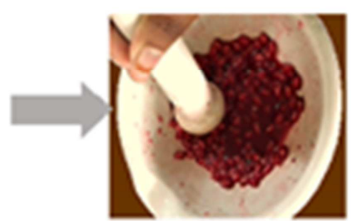

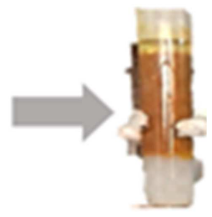

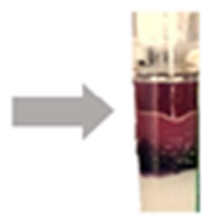

Figure 1. Two of the plants (a) Curcuma longa rhizome, (b) Punica granatum fruit along with its respective plant parts, paste and extracted solution.

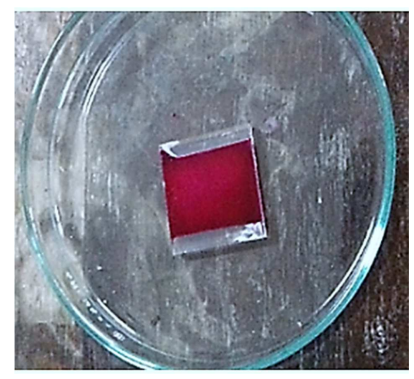

Figure 2. Soaking of $\mathrm{TiO}_{2}$ film in Beta vulgaris dye.

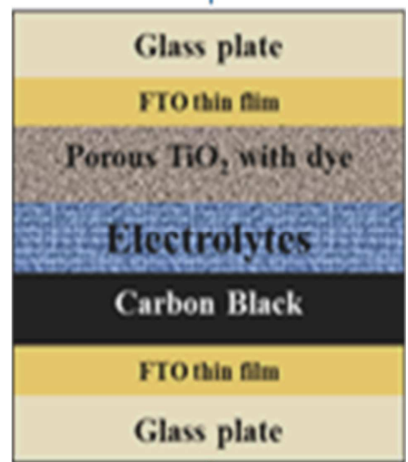

Figure 3. Structure of DSSCS.

\subsection{Preparation of Electrolyte}

The electrolyte solution was prepared by mixing Potassium iodide and iodine in 1:1 ratio.

\subsection{Fabrication of Dye Solar Cell}

A few drops of electrolyte were applied symmetrically on the $\mathrm{TiO}_{2}$ film surface of the electrode. It was then covered by the counter electrode. The plates were gently pressed together and were clipped together for storing in a dark room to avoid intense light, which may create stability problem of the cell.

\subsection{Measurement and Characterization}

The fabricated dye-sensitized solar cells were characterized by optical and electrical measurement. The UV-Vis absorbance characteristic of the dyes extracted from eight different plants was studied by Shimadzu UV-1700 Spectrophotometer. The study was performed for the $250 \mathrm{~nm}$ to $750 \mathrm{~nm}$ wavelength region. The fluorescence characteristic for each of the dyes was performed by Shimadzu AA-7000 Atomic Absorption Spectrophotometer. The range of the EM wave was from $200 \mathrm{~nm}$ to $800 \mathrm{~nm}$ with $1 \mathrm{~nm}$ data interval by $6000 \mathrm{~nm} / \mathrm{min}$ scan speed. The maximum power point for the DSSCs was calculated by an EXTECH EX503 multimeter by measuring maximum voltage and current density at $1.0 \mathrm{AM}$ sunlight condition.

\section{Results and Discussions}

\subsection{Optical Performance}

The absorbance spectrum of the dyes is shown in figure 4 . From the figure we can see that the dyes extracted from $B$. vulgaris (figure 4 (b)), C. longa (figure 4 (e)) and A. dentate (figure $4(\mathrm{~g})$ ) shows an excellent characteristic as a sensitizer. They all shows a wide spectrum absorbance characteristics ranging up to $550 \mathrm{~nm}$ to $650 \mathrm{~nm}$ range. The dye which have higher absorbance both at ultraviolet and visible range regarded a suitable sensitizer, and the B. vulgaris, C. longa, and $A$. dentate shows higher absorbance in that range among the tested samples. Moreover, $P$. granatum and $R$. acicularis dye based cells show a moderate absorbance characteristic to be a sensitizer. The absorbance spectrum of Solar cell based on $B$. spectabilis sensitizer shows an average characteristics. Admittedly, the absorbance spectrums of dyes from D. regia, $T$. grandis indicate the solar cell made from those sensitizer may not perform well as they have a poor spectrum response to be a sensitizer. The dyes extracted from $B$. spectabilis, $B$. vulgaris, $P$. granatum, and $A$. dentate shows a peak at a wavelength between $520 \mathrm{~nm}$ to $560 \mathrm{~nm}$ range. In comparison, the absorbance spectrum of $\mathrm{D}$. regia dye and $\mathrm{C}$. longa dye shows a peak at $380 \mathrm{~nm}$ to $420 \mathrm{~nm}$ wavelength range. Among all of the DSSCs, the DSSC with $R$. acicularis sensitizer shows a highest value of absorbance for a considerable spectrum range. Hence extracted dyes from B. spectabilis, B. vulgaris, P. granatum, A. dentate, D. regia and C. longa has absorbance peak almost closely related to chlorophyll and anthocyanin as reported earlier $[13,14]$. Also it can be said that all the cells can perform well if there absorban spectra can be red shifted.

The fluorescence characteristic of the extracted dye based DSSCs are shown in figure 5. The fluorescence spectrums illustrate that all the dyes except dyes from $D$. regia and $R$. acicularis show a peak at fluorescence spectrum at a 
wavelength ranging from $520 \mathrm{~nm}$ to $560 \mathrm{~nm}$. Meanwhile, the dyes extracted from $C$. longa and $R$. acicularis gives an additional peak near a wavelength of $380 \mathrm{~nm}$.

\subsection{Electrical Performance}

The short circuit current density and open-circuit voltage for each of the DSSCs are illustrated in table 1. Here from the table, we can see that the current density and voltage for the DSSC based on $C$. longa sensitizer is the maximum, whereas the DSSC with $D$. regia sensitizer is the minimum. DSSCs with $B$. vulgaris, $R$. acicularis are among the top three based on the values of current density and voltage. Hence, for their superior value DSSCs with C. longa, B. vulgaris, $R$. acicularis

(a)

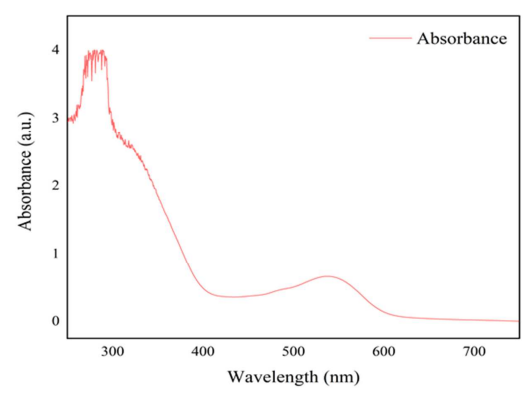

(c)

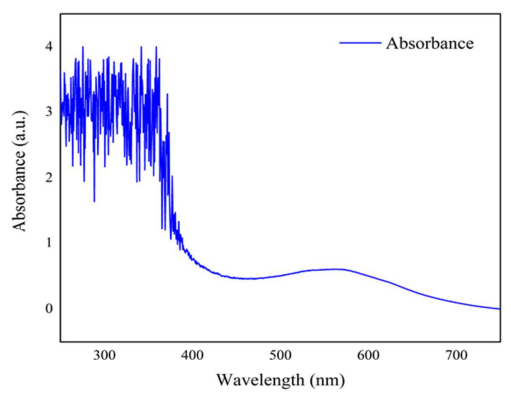

(e)

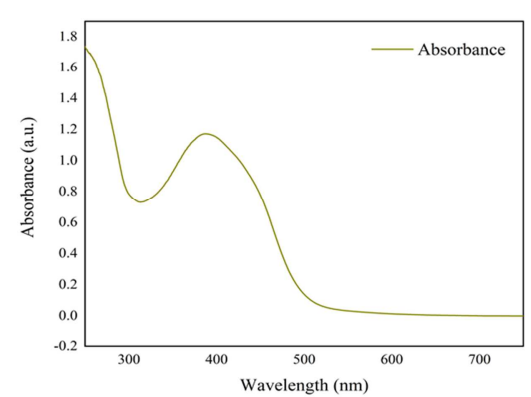

(g)

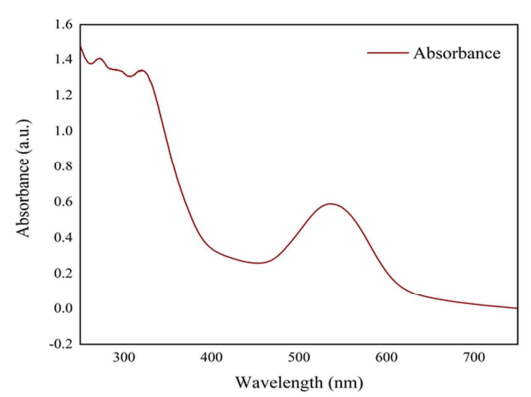

has been considered in the later work.

Table 1. Open circuit voltage and short circuit current density for DSSCs with studied dyes.

\begin{tabular}{lll}
\hline Photosensitizer & $\begin{array}{l}\text { Open circuit voltage, } \\
\mathbf{V}_{\text {oc }}(\mathbf{V})\end{array}$ & $\begin{array}{l}\text { Short circuit current, } \\
\mathbf{J}_{\text {sc }}\left(\mathbf{m A ~} \mathbf{c m}^{-\mathbf{2}}\right)\end{array}$ \\
\hline C. longa & 0.5959 & 1.06 \\
B. vulgaris & 0.5224 & 0.77 \\
R. acicularis & .4849 & 0.74 \\
P. granatum & .4124 & 0.74 \\
T. grandis & .4492 & 0.48 \\
B. spectabilis & .3142 & 0.48 \\
A. dentat & .2928 & 0.34 \\
D. regia & .2638 & 0.35 \\
\hline
\end{tabular}

(b)

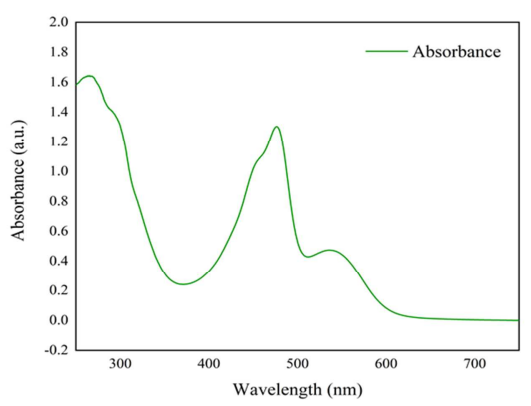

(d)

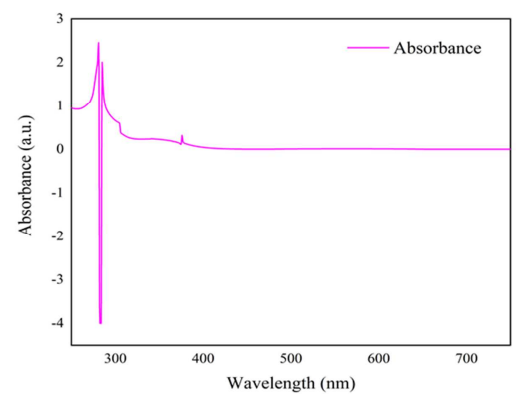

(f)

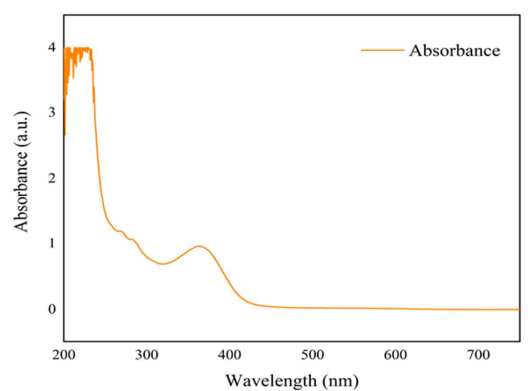

(h)

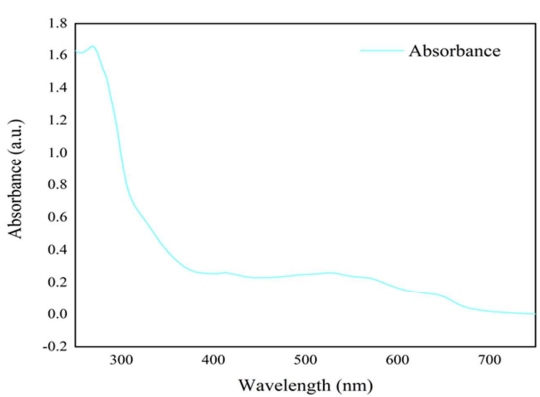

Figure 4. Absorbance characteristic of a) B. spectabilis b) B. vulgaris, c) P. granatum, d) R. acicularis, e) C. longa, f) D. regia g) A. dentate, h) T. grandis based DSSC. 
(a)

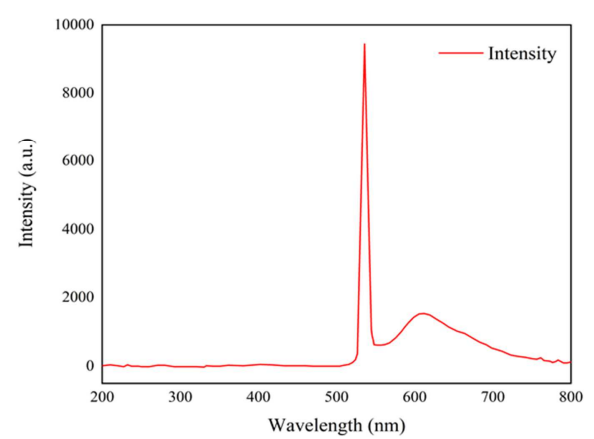

(c)

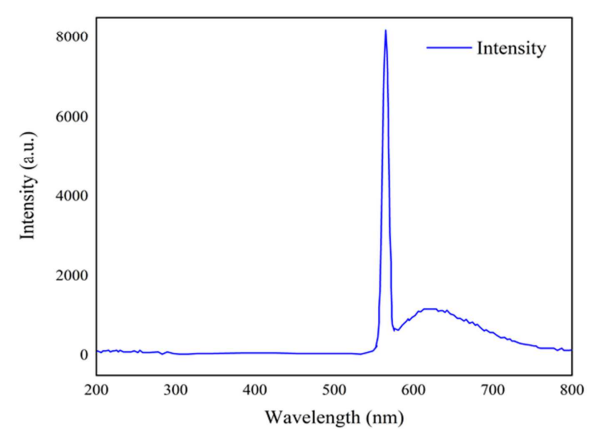

(e)

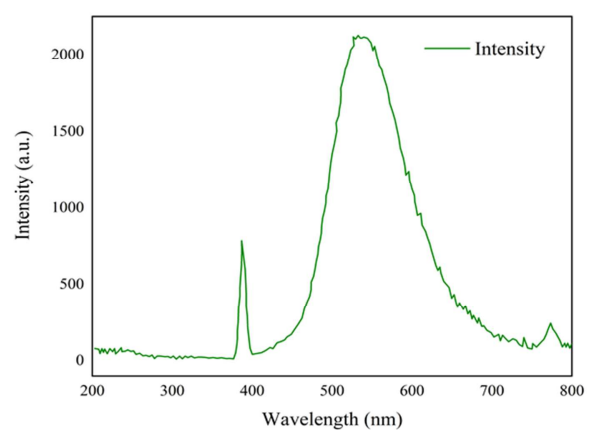

(g)

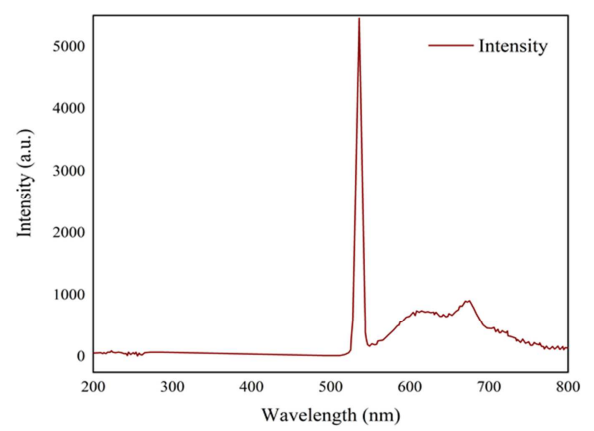

(b)

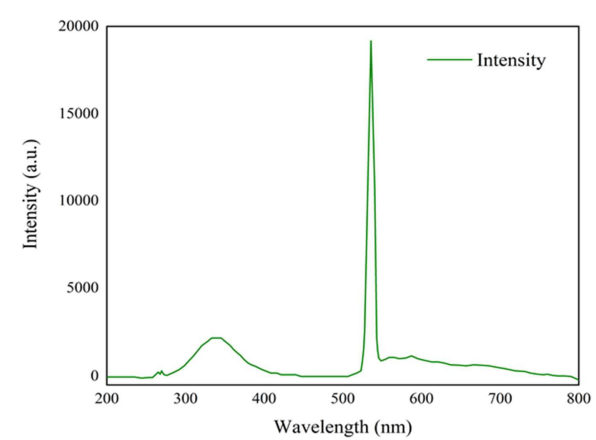

(d)

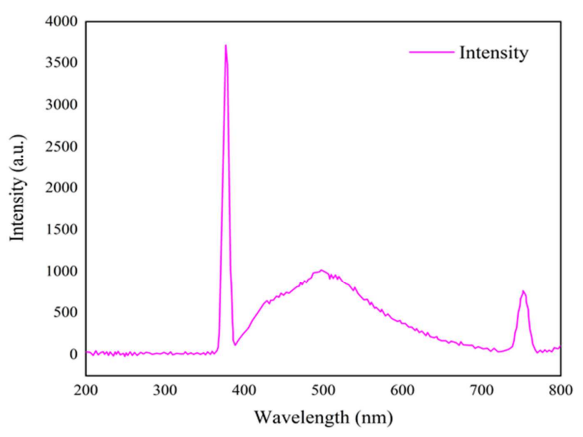

(f)

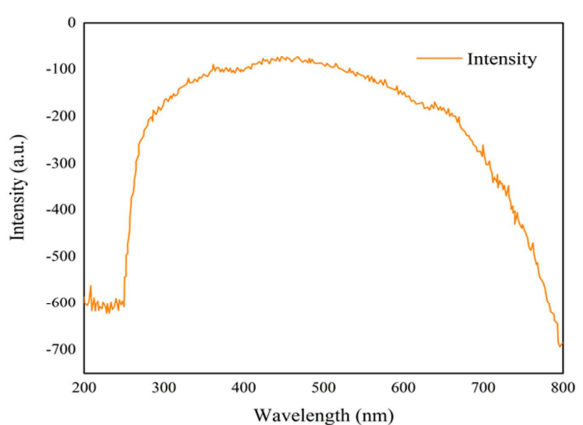

(h)

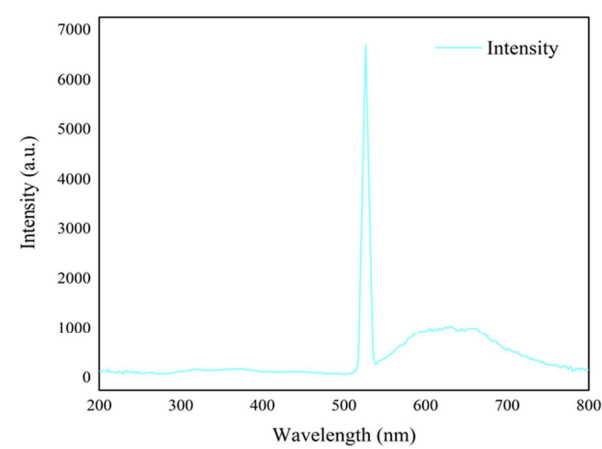

Figure 5. Fluoresence characteristic of a) B. spectabilis b) B. vulgaris, c) P. granatum, d) R. acicularis, e) C. longa, f) D. regia g) A. dentate, h) T. grandis based DSSC

The J-V characteristics of the DSSCs with C. longa sensitizer is given in figure 6 (a), and figure 6 (b) and 6 (c) showed the J-V characteristics for DSSCs based on B. vulgaris and R. acicularis sensitizer. The DSSC based on C. longa shows a higher voltage and current density measurement than DSSCs with B. vulgaris and R. acicularis sensitizer. The fill factor for $C$. longa dye-based DSSC is 0.5977 , while the DSSC based on $B$. vulgaris and $R$. acicularis show a fill factor of 0.56 and 0.3702 respectively. The maximum short circuit current density and open-circuit voltage are found to be $0.8562 \mathrm{~mA} / \mathrm{cm}^{2}$ and $440.9 \mathrm{mV}$. Meanwhile, the DSSCs with $R$. acicularis shows a value of $0.4548 \mathrm{~mA} / \mathrm{cm}^{2}$ and $283.9 \mathrm{mV}$. Hatem et al. also reported the performance of DSSCs based on $R$. acicularis and $P$. granatum family plant as sensitizer. The performance reported here for those is better compared to their work [15]. The J-V characteristic of the DSSCs with the selected three dyes among the eight dyes are summarized on the following table. 
Table 2. J-V characteristic of the DSSCs with selected dyes for study.

\begin{tabular}{llll}
\hline Dyes used for DSSCs & Maximum output voltage $\mathbf{V}_{\mathbf{m p}}(\mathbf{V})$ & Maximum output current $\mathbf{I}_{\mathbf{m p}}\left(\mathbf{m A} / \mathbf{c m}^{2}\right)$ & Fill factor \\
\hline C. longa & 0.4409 & 0.8562 & 0.5977 \\
B. vulgaris & 0.4026 & 0.5848 & 0.56 \\
R. acicularis & 0.2839 & 0.4548 & 0.3702 \\
\hline
\end{tabular}

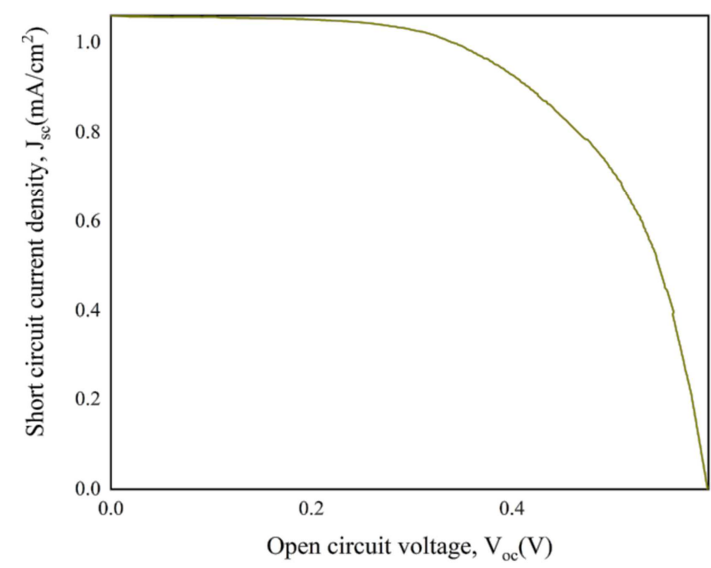

(a)

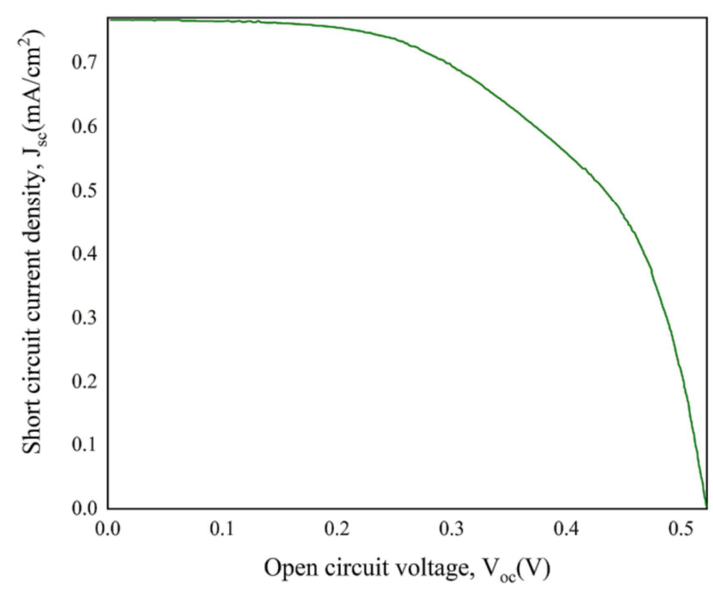

(b)

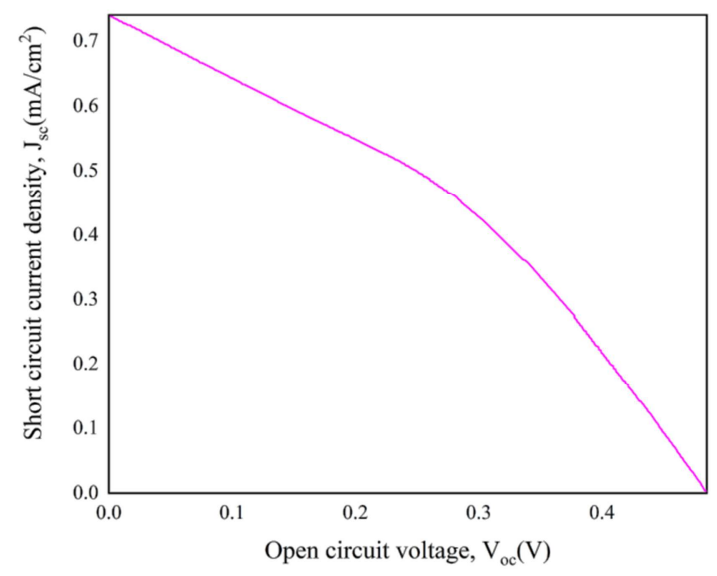

(c)

Figure 6. Short circuit current and open-circuit voltage characteristics for Dye-sensitized solar cell with a) C. longa b) B. vulgaris, c) R. acicularis dye as a sensitizer.

\section{Conclusion}

The natural dye-based DSSCs have shown low PV performance; however, they are regarded as a viable option for sensitizer as the highly efficient Ruthenium based DSSCs has processing complexity and environmental issues. Several natural sources have been reported from time to time in various form to use as a sensitizer. In this work, we used eight natural dyes from various sources, and it is found that $C$. longa dye has the best PV performance. Though $C$. longa dye and $R$. acicularis dye has good and moderate absorbance characteristics respectively, they have a unique feature, a peak near $380 \mathrm{~nm}$ to $400 \mathrm{~nm}$ wavelength, in the fluorescence spectrum. The fill factor that has been found from DSSCs based on $R$. acicularis dye is carefully matched with the previous study [16]. Overall, the natural dyes as photo harvesting element in DSSCs are promising, and the efficiency of DSSCs with natural dyes can be improved by finding proper dye which will have a better interaction between the dye and $\mathrm{TiO}_{2}$ molecules. The performance can also be improved by red shifting the absorbance spectra of all these DSSCs by carefully engineering the sensitizer with suitable substances.

\section{References}

[1] "Dye-Sensitized vs. Thin Film Solar Cells", European Institute for Energy Research, 30 June 2006.

[2] Wang, Peng; Zakeeruddin, Shaik M.; Moser, Jacques E.; Nazeeruddin, Mohammad K.; Sekiguchi, Takashi; Grätzel, Michael (2003). "A stable quasi-solid-state dye-sensitized solar cell with an amphiphilic ruthenium sensitizer and polymer gel electrolyte". Nature Materials. 2 (6): 402-7.

[3] Gratzel, M (2003). "Dye-sensitized solar cells". Journal of Photochemistry and Photobiology C: Photochemistry Reviews. 4 (2): 145-153.

[4] S. A. M Al-Bat'hi, I. Alaei, I. Sopyan, "Natural Photosensitizers for Dye-Sensitized Solar Cells", Int. J. Renew. Energy Res., vol. 3, pp. 138-143, December 2012.

[5] B. O. Regan and M. Gratzel, "A low-cost high efficiency solar cell based on dye sensitized colloidal $\mathrm{TiO}_{2}$ films", Nature, vol. 353, pp. 737-740, October 1991.

[6] Saptadip Saha, Priyanath Das, Ajoy Kumar Chakraborty, Sharmistha Sarkar, Ruchira Debbarma. "Fabrication of DSSC with Nanoporous $\mathrm{TiO}_{2}$ Film and Kenaf Hibiscus Dye as Sensitizer", International journal of renewable energy research Vol. 6, No. 2, 2016.

[7] J. Wu, Z. Lan, J. Lin, M. Huang, Y. Huang, L. Fan, G. Luo, Y. Lin, Y. Xie, and Y. Wei, "Counter electrodes in dye-sensitized solar cells," Chemical Society Reviews, vol. 46, no. 19, pp. 5975-6023, 2017. 
[8] Sharma, K., Sharma, V., \& Sharma, S. S. (2018). Dye-Sensitized Solar Cells: Fundamentals and Current Status. Nanoscale Research Letters, 13 (1).

[9] Wang, Q; Campbell, Wm; Bonfantani, Ee; Jolley, Kw; Officer, Dl; Walsh, Pj; Gordon, K; Humphry-Baker, R; Nazeeruddin, Mk; Grätzel, M (2005). "Efficient light harvesting by using green Zn-porphyrin-sensitized nanocrystalline $\mathrm{TiO}_{2}$ films". The Journal of Physical Chemistry B. 109 (32): 15397-409.

[10] Kexin LI, Zhexun YU, Yanhong LUO, Dongmei LI, Qingbo MENG. Recent Progress of Counter Electrodes in Nanocrystalline Dye-sensitized Solar Cells. J Mater Sci Technol, 2007, 23 (05): 577-582.

[11] A. Kay, and M. Gratzel, "Low cost photovoltaic modules based on dye sensitized nanocrystalline titanium dioxide and carbon powder", Solar Energy Materials \& Solar Cells, Vol. 44, No. 1, pp. 99-117 (1996).

[12] Park JT, Chi WS, Kim SJ, Lee D, Kim JH (2014) Mesoporous $\mathrm{TiO}_{2}$ Bragg Stack Templated by Graft Copolymer for Dye-sensitized Solar Cells. Sci Rep 4: 5505.
[13] Hee-Je Kim, Yeo-Tae Bin, S. N. Karthick, K. V. Hemalatha, C. Justin Raj, S. Venkatesan, Songyi Park, G. Vijayakumar, Natural dye extracted from Rhododendron species flowers as a photosensitizer in dye sensitized solar cell, Int. J. Electrochem. Sci. 8 (2013) 6734e6743.

[14] H. Chang, Y.-J. Lo, "Pomegranate leaves and mulberry fruits as natural sensitizers for Dye-sensitized solar cells," Sol. Energy 84 (10) (2010) 1833e1837.

[15] Hatem S. El-Ghamri, Sofyan A. Taya, Taher M. El-Agez, Amal M. Al-Kahlout, Naji Al Dahoudi, Monzir S. Abdel-Latif, "Natural Dyes as Photosensitizers for Dye-sensitized Solar Cells", Journal of Nano- and Electronic Physics, Vol. 7 No 3, 03001(6pp) (2015).

[16] Gokilamani N, Muthukumarasamy N, thambidurai M, Ranjitha A, Velauthapillai D, Senthil TS, Balasundaraprabhu R (2013) Dye-sensitized solar cells with natural dyes extracted from rose petals. J Mat Sci Mat Electron 24 (9). 